\title{
Los desafíos de la construcción sindical en tiempos de prohibición de demandas salariales. Un estudio de caso: la Juventud Trabajadora Peronista en Argentina (1973-1974)
}

\author{
The challenges of union building in times of prohibition of wage \\ demands. A case study: the Peronist Working Youth in Argentina \\ (1973-1974)
}

\section{Guido Lissandrello*}

Resumen: En este artículo nos proponemos estudiar el desarrollo de la Juventud Trabajadora Peronista (JTP), organización sindical adscripta a la organización peronista Montoneros, durante los años 1973 y 1974. En aquellos años estuvo en vigencia el Pacto Social del gobierno peronista que prohibía las negociaciones salariales. Nos interesa estudiar cómo se desarrolló la construcción sindical en dicho contexto. Sostenemos como hipótesis que la JTP se construyó impulsando los reclamos en torno a la salubridad y la higiene en el proceso de trabajo y que, para ello, se desarrolló una particular articulación con el Instituto de Medicina del Trabajo (IMT) de la Universidad de Buenos Aires, que le permitió estar en mejores condiciones para impulsar esa estrategia.

Palabras claves: Izquierdas; Sindicalismo; Peronismo.

Abstract: In this article we propose to study the development of the Juventud Trabajadora Peronista (JTP), a union organization attached to the Peronist organization Montoneros, during the years 1973 and 1974. In those years the Social Pact of the Peronist government was in force, prohibiting wage negotiations. We are interested in studying how union construction developed in this context. We hypothesize that the JTP was built by promoting claims about

* Doctor de la Universidad de Buenos Aires, área Historia. Profesor de Métodos Cuantitativos en la Universidad de Buenos Aires con una beca postdoctoral del CONICET. ORCID: https://orcid.org/0000-0003-0380-0460. E-mail: g.lissandrello@hotmail.com. 
health and hygiene in the work process and that, for this, a particular link was developed with the Institute of Occupational Medicine (IMT) of the University of Buenos Aires, which allowed him to be in better conditions to promote that strategy.

Keywords: Lefts; Syndicalism; Peronism.

\section{Introducción}

$\mathrm{H}$ STÓRICAMENTE, las izquierdas buscaron vincularse a un sujeto que, entendían, era el principal vector de cualquier transformación social: la clase obrera. Ello direccionó la actividad partidaria a un espacio particular, las fábricas y los sindicatos. Allí debían desplegarse tareas de acercamiento, que implicaban apoyar y estimular las demandas laborales de los trabajadores, e introducir gradualmente los objetivos políticos de las organizaciones. Esto fue teorizado profusamente por el líder del Partido Bolchevique, Vladimir Lenin ${ }^{1}$, pero lo cierto es que estos planteos excedieron a las izquierdas marxistas.

En la década del '70, América Latina fue escenario de grandes conflictos sociales, con movilizaciones callejeras y una importante efervescencia fabril. El continente asistió a la emergencia de nuevas organizaciones políticas, que buscaban distanciarse de lo que consideraban ya una "izquierda tradicional". Ese nuevo espacio estuvo surcado por grandes debates, entre ellos el de la estrategia de lucha armada, su pertinencia y su adaptación a contextos urbanos, el problema del camino pacífico al socialismo, el compromiso y la militancia de los intelectuales y el problema continental o internacional de la revolución. ${ }^{2}$

Argentina, en ese contexto, fue uno de los países más convulsivos. Desde el llamado Cordobazo (1969), una huelga política de masas $^{3}$ que puso en jaque a la dictadura conocida como Revolución Argentina, se produjo una importante movilización social que solo fue interrumpida siete años después, con el llamado Proceso de Reorganización Nacional (1976), la dictadura más feroz que viviría el país.

En ese contexto de efervescencia social, las izquierdas comenzaron a crecer y a encontrar eco en su prédica política. Naturalmente, esto se tradujo en los intentos por alcanzar influencia en los sindicatos, intentos que en ocasiones tuvieron una recepción positiva y le permitieron conquistar cuerpos de delegados y comisiones internas. Este proceso ha sido estudiado parcialmente por la bibliografía, si bien la mirada tendió a posarse sobre las construcciones guerrilleras de las izquierdas influidas por la Revolución Cubana.

Existe, entonces, una pregunta que aún no ha sido respondida en profundidad y que abre un terreno fecundo para las investigaciones. ¿Qué práctica política desplegaron las izquierdas en los sindicatos en una etapa convulsionada como la que recorrió a Argentina

1 LENIN, Vladimir. ¿Qué hacer? Buenos Aires: Luxemburg, 2007.

2 MARCHESI, Aldo. Hacer la revolución. Buenos Aires: Siglo XXI, 2019.

3 BALVÉ, Beba; BALVÉ, Beatriz. El 69. Buenos Aires: Ediciones ryr, 2005. 
entre 1969 y 1976 ? A los efectos de comenzar a estudiar este fenómeno, en este artículo nos abordamos el desarrollo de la Juventud Trabajadora Peronista (JTP), organización sindical adscripta a la organización peronista Montoneros, durante los años 1973 y 1974. Esta delimitación temporal no es azarosa, responde a una coyuntura particular. Al comienzo de ese período llegaba al poder el peronismo, tras 18 años de proscripción. Esa experiencia de gobierno arribaba con una propuesta política particular, el llamado "Pacto Social" que implicaba un acuerdo entre trabajadores y empresarios, a partir del cual se buscaba una armonía sobre la base de la prohibición de las negociaciones salariales. De este modo, nos preguntamos cómo se desarrolló la JTP en un contexto en que en que la presidencia (primero en manos de Héctor Cámpora y luego de Juan Domingo Perón), que se identificaba en la misma tradición política de la organización, prohibió las luchas por aumentos salariales. Naturalmente, aquella era la principal demanda de los trabajadores y tradicionalmente las izquierdas siempre habían intervenido impulsándola. El nuevo escenario abierto obligaba a innovaciones estratégicas. Sostenemos como hipótesis que la respuesta al interrogante sobre la construcción sindical se encontró en el impulso a los reclamos en torno a la salubridad y la higiene en el proceso de trabajo y que, para ello, se desarrolló una particular articulación con el Instituto de Medicina del Trabajo (IMT) de la Universidad de Buenos Aires, que le permitió a la JTP estar en mejores condiciones para impulsar esa estrategia.

Nuestro trabajo se basa en el estudio de documentos escritos y fuentes orales. En cuanto a los primeros, utilizamos documentos internos de la JTP y de Montoneros, que nos permiten dar cuenta de sus posicionamientos políticos. Del mismo modo, hacemos uso de los textos producidos por el IMT, lo que nos permite ahondar en el conocimiento producido por este con relación a las condiciones de salubridad e higiene de diferentes ramas de la producción. Finalmente, los periódicos de las izquierdas, de Montoneros y otras organizaciones, nos permitieron reconstruir el desarrollo fáctico de los conflictos obreros. Por otro lado, recurrimos a testimonios orales ya elaborados por el Centro de Documentación "Pensar en Salud" (CeDoPS), que estudió la experiencia del IMT entrevistando a médicos y profesionales que formaron parte de ella. Asimismo, incorporamos entrevistas elaboradas por nosotros a dirigentes de la JTP.

El presente artículo comienza con un breve estado del arte, para luego reconstruir sintéticamente la propuesta política de la JTP y el contexto nacional signado por el Pacto Social. Continuamos examinando la emergencia del IMT y estudiamos su articulación con la agrupación sindical de Montoneros. Finalmente, exponemos las principales ramas de la economía donde la articulación IMT-JTP tuvo lugar, mostrando su desarrollo concreto. 


\section{Sumario estado de la cuestión}

EL CAMPO DE LOS ESTUDIOS sobre la medicina del trabajo, los llamados accidentes laborales y la seguridad social, en Argentina, ha sido un terreno fecundo. Se destacan allí los trabajos de Ramacciotti, quien ha destacado la primacía de la lógica indemnizatoria por sobre la preventiva en la legislación laboral argentina, ${ }^{4}$ a la par que ahondó en el estudio de los procesos de capacitación en salud pública, ${ }^{5}$ las perspectivas analíticas sobre los accidentes laborales y enfermedades profesionales, ${ }^{6} \mathrm{O}$ el involucramiento del Estado en las políticas sanitarias en los '50 y ' $60,{ }^{7}$ entre otras. Sin embargo, nuestro trabajo no apunta en esta dirección, sino que pretende abarcar el campo de las estrategias de izquierda en el mundo sindical.

El estudio del sindicalismo en los años '70 en Argentina no ha sido un terreno inexplorado. Colocando la mirada en las cúpulas sindicales, se ha señalado que en el período 1973-1976 los sindicatos se integraron al gobierno ${ }^{8}$ y debieron resistir las presiones de las bases ${ }^{9}$. Como contrapunto, también se estudió el fenómeno desde las bases, reconstruyendo las luchas obreras desde 1955, con el inicio de la llamada "resistencia peronista"10 hasta el "Cordobazo", haciendo hincapié en el fenómeno del clasismo, como resultado de la articulación de las izquierdas con la clase obrera radicalizada ${ }^{11}$. Trabajos específicos sobre la fundación de organismos de coordinación obrera en el año 1975, ante la política de shock conocida como Rodrigazo, ahondan en la presencia de las izquierdas en el movimiento obrero ${ }^{12}$. Sin embargo, las estrategias por las cuales las organizaciones lograron penetrar en los trabajadores, sigue siendo un terreno poco abordado.

La bibliografía sobre Montoneros es extensa, y abarca diferentes problemáticas, desde sus orígenes católicos hasta su estrategia militar, pasando por la compleja relación con el líder del movimiento, entre otros aspectos. No es la pretensión de este artículo ahondar en ello. En cuanto a la JTP como observable específico, son pocos los estudios existentes, debido a que en general se ha sostenido que la estrategia central de la organización era el desarrollo

4 RAMACCIOTTI, Karina; MADDALENA, Pablo. ¿Mejor prevenir que indemnizar? Los accidentes de trabajo en Argentina, 1915-1955. Dynamis, Granada, v. 39, n. 2, p. 311-330, 2019.

5 BIERNAT, Carolina; RAMACCIOTTI, Karina; RAYEZ, Federico. La capacitación en salud pública en la Argentina entre 1900-1960. Unisinos, São Leopoldo, v. 22, n. 4, p. 637-650, 2018.

6 RAMACCIOTTI, Karina. Perspectivas analíticas sobre la cuestión de los accidentes de trabajo y enfermedades profesionales. Primera mitad del siglo XX. Estudios sociales, Santa Fé, v. 49, n. 2, p. 85-93, 2015.

7 RAMACCIOTTI, Karina. Saberes médicos y Políticas sanitarias en la Argentina durante la Guerra fría. Boletín Científico Sapiens Research, v. 5, p. 25-35, 2015.

8 TORRE, Juan Carlos. El gigante invertebrado. Los sindicatos en el gobierno, 1973-1976. Buenos Aires: Ceal, 1983.

9 JELIN, Elizabeth. Conflictos laborales en la Argentina, 1973-1976. Buenos Aires: CEDES, 1977.

10 SCHNEIDER, Alejandro. Los compañeros. Trabajadores, izquierda y peronismo. 1955/1973. Buenos Aires: Imago Mundi, 2006; JAMES, Daniel. Resistencia e integración. Buenos Aires: Siglo XXI, 2010.

11 MIGNON, Carlos. Córdoba obrera. El sindicato en la fábrica 1968-1973. Buenos Aires: Imago Mundi, 2014; GORDILLO, Mónica. Córdoba en los '60: la experiencia del sindicalismo combativo. Córdoba: UNC, 1996; BRENNAN, James; GORDILLO, Mónica. Córdoba Rebelde. El Cordobazo, el clasismo y la movilización social. La Plata: De la Campana, 2008; BRENNAN, James. El Cordobazo. Las guerras obreras en Córdoba, 1955-1976. Buenos Aires: Sudamericana, 1996.

12 LÓBBE, Héctor. La guerrilla fabril. Buenos Aires: Ediciones ryr, 2006; WERNER, Ruth y AGUIRRE, Facundo. Insurgencia obrera en la Argentina 1969-1976. Clasismo, Coordinadoras Interfabriles y estrategias de la izquierda. Buenos Aires: IPS, 2007. 
guerrillero más que sindical ${ }^{13}$. Pacheco ha reconstruido la presencia de este organismo en el movimiento obrero, mostrando las ramas en las que estuvo inserto y las luchas de las que fue parte. ${ }^{14}$ Sin embargo, allí no se interroga por la estrategia con la cual la JTP logró construirse aún en un contexto donde estaba vedada la lucha salarial. Por su parte, Lorenz estudió el caso particular de crecimiento de esta organización en los Astilleros ASTARSA y ahondó en las luchas por las condiciones de salubridad e higiene, aún sin ubicar esta apuesta como parte de una opción política deliberadamente delineada por Montoneros y su JTP. ${ }^{15}$

Como puede apreciarse, un estudio del tipo que nos proponemos aquí, que indague las estrategias de desarrollo de la JTP en un contexto muy particular, signado por la clausura de las luchas salariales, no ha sido aún realizado. Creemos que empezar a transitar el estudio de esta compleja trama, puede iluminar tanto el conocimiento disponible sobre las izquierdas y sus vinculaciones sindicales en una etapa signada por la alta conflictividad social.

\section{Montoneros, la JTP y el Pacto Social' ${ }^{16}$}

Desde sus comienzos EN 1970, Montoneros se definió como parte integrante del Movimiento Peronista. De acuerdo a sus concepciones políticas, era ese el motor del proceso revolucionario. Dado que caracterizaba a la Argentina como un capitalismo dependiente, cuyo pleno desarrollo había sido obstaculizado por la acción del imperialismo, defendía la necesidad de impulsar un programa de Liberación Nacional, que abriría el camino al Socialismo nacional. Ello conllevaba a una alianza de la clase obrera con las fracciones de la burguesía más perjudicadas, es decir, aquellas nacionales de tamaño chico y mediano. Con ellas se podría construir un capitalismo liberado de las ataduras imperialistas. El peronismo era visualizado como el ámbito en que estas dos fracciones podían encontrarse, siempre bajo el liderazgo de Perón. ${ }^{17}$ La organización desarrolló su propio frente sindical en 1973, la JTP, con una estrategia orientada a conquistar la representación de los trabajadores dentro del movimiento y desalojar a la llamada burocracia sindical del brazo sindical del movimiento peronista: las 62 Organizaciones. Esto no implicó cuestionar el liderazgo de Perón ni impugnar la presencia de fracciones burguesas en el peronismo. Por el contrario, pretendía alcanzar una representación

13 GILLESPIE, Richard. Montoneros. Soldados de Perón. Buenos Aires: Grijalbo, 1987; SALCEDO, Javier. Los Montoneros del barrio. Buenos Aires: Eduntref, 2011.

14 PACHECO, Julieta. Análisis de la militancia sindical de montoneros: la juventud trabajadora peronista y sus luchas. E-I@tina, v. 13, n. 50, p. 1-16, 2015; PACHECO, Julieta. La izquierda peronista y su inserción en el movimiento obrero. Juventud trabajadora peronista-Montoneros, 1970-1976. Revista Latino-americana de Estudos do Trabalho, n. 32, p. 157-184, 2014.

15 LORENZ, Federico. Algo parecido a la felicidad. Una historia de la lucha de la clase trabajadora durante la década del setenta (1973-1978). Buenos Aires: Edhasa, 2013; LORENZ, Federico. Los zapatos de Carlito. Una historia de los trabajadores navales de Tigre en la década del setenta. Buenos Aires: Grupo Norma, 2007.

16 Un análisis sobre la JTP y el Pacto Social puede verse en: LISSANDRELLO, Guido. Montoneros y el Partido Revolucionario de los Trabajadores - Ejército Revolucionario del Pueblo ante el Pacto Social. Izquierdas, $n$. 13, p. 83-108, 2012.

17 Estos planteos pueden verse en los siguientes documentos: MONTONEROS. Boletín Interno n. 1, 1973. MONTONEROS. Charla de la Conducción Nacional ante las agrupaciones de los frentes, 1973. MONTONEROS. Línea político militar, 1971. 
honesta y combativa de los trabajadores. ${ }^{18}$ Con esta estructura, Montoneros se dispuso a conquistar comisiones internas, cuerpos de delegados, seccionales, sindicatos y federaciones.

Lanzada públicamente en abril de 1973, a pocas semanas de andar la JTP se encontró frente a un escollo tarea. El gobierno peronista del electo Héctor Cámpora firmaba el llamado "Pacto Social", medida que buscaba compatibilizar los intereses de los trabajadores y de los empresarios para apuntalar la economía, amortiguar la inflación y aumentar la participación de los asalariados en el ingreso nacional. Para ello el empresariado nucleado en la Confederación General Económica (CGE) se comprometía al congelamiento de precios y aceptaba un alza general de salarios, y los trabajadores, representados por el entonces secretario general de la Confederación General de Trabajadores (CGT) José Ignacio Rucci, aceptaban la suspensión de la negociación colectiva sobre el salario durante el plazo de dos años.

Montoneros defendió esta medida, que consideraba acorde a su programa de liberación nacional:

\begin{abstract}
El Pacto Social, podemos decir que es un acuerdo, o debería ser un acuerdo, que formaliza la alianza de clases, pero regido y gobernado por la clase trabajadora... debería ser. Pero en la actualidad el Pacto Social no refleja eso, y no refleja eso porque en la constitución de esa alianza los trabajadores no tienen representantes... Porque tienen allí, en la CGT, una burocracia con cuatro patas que no representa ni a su abuela... [...] Es decir, no es que nosotros estemos en contra de la existencia de un Pacto Social sino que creemos que éste no refleja los intereses de los trabajadores y por lo tanto deberá ser modificado. ${ }^{19}$
\end{abstract}

Este diagnóstico confirmaba la necesidad de construir la JTP, para desalojar a los dirigentes sindicales juzgados como carentes de legitimidad. Esa tarea, sin embargo, chocaba con la defensa del Pacto que vedaba la lucha salarial. El frente sindical debía crecer entonces sin impulsar reclamos de ese tipo, lo que obligó a buscar alternativas. Allí se volvió clave la articulación con el IMT.

\title{
El Instituto de Medicina del Trabajo 20
}

EL IMT FUE EL RESULTADO de dos fenómenos que se dieron en paralelo entre fines de 1972 y comienzos de 1973. Por un lado, la incorporación a Montoneros de un pequeño núcleo militante llamado "Los Obreros", entre los cuales se destacaba Ricardo Saiegh, un médico que había trabajado en colaboración con sindicatos de Córdoba, a partir del estudio de las condiciones de trabajo. ${ }^{21}$ Por otro, la creciente influencia de la Juventud Universitaria Peronista (JUP) en la UBA, en particular la designación de Mario Testa, hombre afín a la Juventud Peronista, como

18 JUVENTUD TRABAJADORA PERONISTA. Lineamientos políticos, 1973.

19 EL DISCURSO de Firmenich. EI Descamisado, Buenos Aires, p. 5-7, 28 ago. 1973.

20 Para este acápite nos basamos en MARTIN, Ana Laura; SPINELLI, Hugo. Para que el hombre vuelva a cantar mientras trabaja. El Instituto de Medicina del Trabajo (IMT) y la salud de los trabajadores. Salud colectiva, Lanus, v. 7, n. 2, p. 177-197, mayo/agosto 2011.

21 SAIEGH, Ricardo. Entrevista. Entrevista cedida al CEDOPS, Lanús, Buenos Aires, 2009. 
Delegado Interventor y Decano de la Facultad de Medicina. Bajo esa gestión fue presentado el proyecto del IMT que encabezaba Saiegh junto a otro médico, Ricardo Efron, y comenzó a trabajarse en su puesta en marcha. En efecto, el "ascenso" dentro de la Universidad de quienes serían la dirección del Instituto no fue producto de trayectoria académica -si bien habían desarrollado trabajos de investigación dentro de la problemática, no contaban con los "avales" académicos para ocupar esos puestos-, sino de la influencia política que había logrado Montoneros a través de la JP y la JUP. ${ }^{22}$

El 16 de julio de ese año fue oficializada la creación del IMT mediante una resolución firmada por Testa. En ella se indicaba que a partir de 1955 se había iniciado un proceso de entrega del país y opresión al pueblo que se tradujo en un deterioro progresivo de la salud de los trabajadores. Como parte de esa entrega se habría constituido una Medicina del Trabajo afín a la opresión y la Facultad de Medicina, tanto en su plan de estudios como en sus espacios de investigación, había ignorado los aspectos patógenos del trabajo. De este modo, se consideraba necesario "poner la facultad al servicio del pueblo", para lo cual era menester "desarrollar una Medicina del Trabajo realmente al servicio de los trabajadores"23. EI IMT debía cumplir esa tarea para lo cual se le encargaban funciones de docencia estudiantil y de graduados, investigación, acopio de información, documentación y bibliografía laboral, asesoramiento laboral, extensión universitaria y formación de auxiliares de la salud laboral. Se le asignaba además una tarea de apoyo al gobierno, en la medida que "el Instituto abordará el estudio de las normas que protejan la salud del trabajador, a efectos de proponer al Parlamento tal legislación"24 (IMT, 1973b:12).

Al analizar el programa del Instituto nos encontramos con una significativa coincidencia con los planteos políticos de Montoneros y la JTP. El documento fundacional del IMT, identifica las tareas del organismo como parte del "proceso de reconstrucción nacional en que se halla empeñado nuestro pueblo desde que se instauró en nuestro país el Gobierno Nacional y Popular presidido por el compañero Cámpora y conducido por el Teniente General Perón"25. En la Mesa Redonda "La salud en las fábricas" que se celebró el primero de agosto como forma de lanzamiento público del Instituto, con la presencia de Testa, Saiegh, Alberto Ozores (Interventor del Hospital Escuela de Medicina) y dirigentes obreros ${ }^{26}$ se desarrolló con más claridad esta línea. Testa señaló que contra la medicina propia de un país "oligárquico, capitalista y dependiente" la salud aparece como mercancía. Sin embargo,

¡Cómo cambian las cosas con Perón en el Poder! Perón es la alternativa a la dependencia; significa la liberación y la garantía de lucha contra la oligarquía, porque es el líder de las masas populares argentinas y quien abre la posibilidad de la marcha definitiva hacia el socialismo nacional. ${ }^{27}$

22 AGUERRE, Felipe. Entrevista. Entrevista cedida al CEDOPS. Lanús, Buenos Aires, 2010.

23 INSTITUTO DE MEDICINA DEL TRABAJO. Fundamentos de su creación, jul. 1973, p. 11.

24 INSTITUTO DE MEDICINA DEL TRABAJO. Boletín del Instituto de Medicina del Trabajo $\mathbf{n}^{\circ} \mathbf{1 ,} 1973$, p. 12.

25 INSTITUTO DE MEDICINA DEL TRABAJO. Fundamentos de su creación, jul. de 1973, p. 1.

26 MEDICINA laboral o carnicería. Ya! Es tiempo de pueblo. Buenos Aires, p. 20-21, 10 ago. 1973. Los que dejan la salud en el trabajo. Noticias. Buenos Aires, p. 11. 28 dic. 1973.

27 INSTITUTO DE MEDICINA DEL TRABAJO. Boletín del Instituto de Medicina del Trabajo nº 1, 1973, p. 18. 
En efecto, desde los fundamentos del Instituto se recuperaba la acción de Perón en la Secretario de Trabajo y Previsión y en sus dos primeros gobiernos, señalando que produjo un avance sustantivo en la protección de la salud del trabajador rural, de los accidentes y las enfermedades profesionales. Ramón Carrillo como encargado del Ministerio de Salud Pública y Germinal Rodríguez, como titular de la Cátedra de Higiene y Medicina Social de la Facultad de Medicina, habrían sido los adalides de este desarrollo en la Medicina del Trabajo que plantearía una serie de innovaciones que el IMT buscaba recuperar. Ellas serían: 1. Dotar a los trabajadores y gremios de autoridad efectiva en el control sanitario de los establecimientos industriales. 2. Emprender una actividad educativa para que las discusiones entre patrones y obreros no se reduzcan a horarios y salarios y olviden a menudo la salud. 3. La creación de la especialidad de médicos de fábrica y asistente industrial para la capacitación. 4. Una concepción epidemiológica de la enfermedad que no se limite a las enfermedades profesionales sino a las enfermedades del trabajo pues "casi no hay enfermedad que no tenga en las formas de trabajo un elemento que pueda agravarlo". ${ }^{28}$ En este sentido, la perspectiva de la medicina laboral propuesta por el IMT, se distancia notablemente del precepto que regía el marco regulatorio legal de la Argentina, que apuntaba a atenuar los efectos de las lesiones acontecidas en ámbitos de trabajo. ${ }^{29}$

A partir de la caída del peronismo en 1955 estos avances y toda su legislación laboral habrían caído en desuso, verificándose un "deterioro progresivo de la salud del trabajador y su familia" como resultado del aumento de los ritmos de trabajo, la prolongación de la jornada laboral, la inseguridad, el régimen represivo y la caída del salario real. Todo ello con "la complicidad de muchos sindicalistas burocratizados que estaban en connivencia con el régimen de la dictadura". Así se configuraría una particular Medicina del Trabajo que es el producto del "régimen capitalista dependiente" y que es catalogada como una medicina policial al servicio "incondicional [de] los intereses de los detentores del poder económico". ${ }^{30}$

Este tipo de medicina posicionaría al médico ya no como un "tratante" que busca un diagnóstico correcto y el tratamiento de la enfermedad, sino como un "policía" destinado al control del ausentismo, siendo su función demostrar la veracidad de la enfermedad aducida por el trabajador. En sintonía con ello, el trabajo como agente patógeno sería eliminado de los planes de estudio y, consecuentemente, quedaría fuera del campo de análisis de los futuros médicos.

Podemos encontrar ciertos elementos de similitud entre los planteos programáticos de Montoneros y el IMT. En efecto, ambos coinciden en señalar que la Argentina experimentó una etapa de liberación durante los dos primeros gobiernos peronistas, que luego fue desarticulada

28 INSTITUTO DE MEDICINA DEL TRABAJO. Fundamentos de su creación, jul. de 1973, p. 3-4.

29 RAMACCIOTTI, Karina. Los accidentes laborales en perspectiva histórica. Buenos Aires: Ediciones UNGS, 2015.

30 Ibidem, p. 5. 
producto de 18 años de dictaduras y dominio de la "oligarquía". Concuerdan en señalar que en esa etapa fue clave la colaboración de las direcciones sindicales burocratizadas, que permitieron, para el caso específico al que se aboca el IMT, la degradación de las condiciones de salubridad de los trabajadores. Finalmente, ambos defienden el regreso del peronismo al poder como una etapa de reconstrucción y liberación que conducirá al socialismo nacional.

Bajo este programa, el IMT se propuso dar nacimiento a una nueva concepción de la Medicina del Trabajo. Su accionar cubrió tres planos: la formación, la investigación y el asesoramiento a comisiones internas, cuerpos de delegados y sindicatos.

En cuanto a la investigación y la asistencia, esa fue la apuesta más fuerte del Instituto, lo que singularizó su experiencia y lo conecta con la JTP. Aquí nos detendremos en señalar la metodología de trabajo en este ámbito para, en el siguiente acápite, estudiar la relación con el frente sindical montonero. La investigación del IMT tenía como objetivo abordar el problema de la salud de los trabajadores atendiendo a la interrelación entre el entorno socioeconómico y las condiciones laborales. Buscaba, con ello, desprenderse de la concepción que consideraba tradicional según la cual existía una causa única que genera un cuadro clínico definido, lo que se denominaba enfermedad profesional. En oposición a ello, se defendía la multicausalidad de la patología del trabajo, lo que implicaba todas las afecciones que podía producir el ambiente de trabajo, la salud mental y las condiciones de vida del trabajador, mediadas por el deterioro del ingreso. Naturalmente, eso condujo al desarrollo de un trabajo de tipo multidisciplinar: en el campo de la Medicina y la Salud, además de médicos participaron psicólogos y toxicólogos; en el campo de las Ciencias Sociales, para el estudio de las vaciables socioeconómicas, confluyeron sociólogos, antropólogos y economistas; desde las llamadas Ciencias Exactas, ingenieros que aportaron el conocimientos técnico y el instrumental necesario para la realización de las mediciones de ruido, para lo cual se realizaron acuerdos con la cátedra de Electroacústica de la Facultad de Ingeniería, y también químicos para las pruebas toxicológicas; y abogados para la elaboración de modificaciones en la legislación laboral.

Para cada investigación se formaba un equipo de trabajo cuya composición se decidía a partir de un primer acercamiento a la rama de la producción. Allí se procedía a la recolección de información sobre los problemas y condicionamientos particulares de cada industria. Generalmente este procedimiento se realizaba por medio de entrevistas que brindaban información general sobre condiciones laborales. Se pretendía de este modo que "todos los programas tuvieran nacimiento en un reclamo concreto de la realidad." 31 Detectados los problemas centrales de la actividad, se pasaba a la etapa de planeamiento, donde cada uno de los especialistas estudiaba desde su punto de vista las patologías, se elaboraba el instrumental para concretar la investigación, y se determina qué estudios médicos se realizarían sobre los pacientes-trabajadores. Todo ello, finalmente, se procesaba a través del Área Biomédica del

$\overline{31 \text { Ibidem, p. } 4 .}$ 
Servicio Universitario de Computación. Una vez que se habían detectado todas las patologías características de ese trabajo y sus fuentes, se elaboraba un informe final y se establecían criterios para la prevención y/o evasión de las afecciones. Con ese material, se esperaba que las comisiones internas y cuerpos de delegados pudieran trabajar.

Dentro del Instituto se desarrollaron varios programas. El más acabado fue el de Telefónicos, destinado al estudio de las condiciones de trabajo y de salud de las operadoras telefónicas, particularmente en lo que atañe a su salud mental. Otra de las líneas que alcanzó un desarrollo considerable fue el programa de mineros, con relevamientos en minas "El Aguilar" y "Pirquitas" de la provincia de Jujuy, siendo la afección principal la neumoconiosis. Existió también un programa de metalmecánicos, donde el eje vertebrador fue la intoxicación por plomo que producía saturnismo; uno de ceramistas con particular énfasis en las altas temperaturas, el polvo, el ruido y el trabajo pesado; $y$, sobre accidentes de trabajo en la industria naval. Otros programas tuvieron un desarrollo y alcance menor: textiles, ferroviarios, no docentes de la Universidad de Buenos Aires, sobre envejecimiento y trabajo, y sobre ruido en la industria para actualizar los umbrales de audibilidad que regían la legislación laboral vigente.

\section{La articulación IMT-JTP}

MÁs ALLÁ DEL PERFIL INSTITUCIONAL y la diversidad ideológica imperante en las filas del IMT, en el conjunto "había una afinidad, llamale ideológica, con el camporismo"32 (Kujnisky, 2009). Guillermo Greco, líder de la JTP, lo confirma al mencionar su rol como articulador con el Instituto.

Los orígenes de esa articulación se remontan, en buena parte, a la experiencia de los Astilleros Argentinos Río de La Plata S.A. (ASTARSA), ubicados en Tigre, que habían sido tomados por sus trabajadores a comienzos de 1973 en reclamo de mejoras en seguridad. Allí confluyeron Los Obreros, la revista que editaba este grupo junto a intelectuales de Pasado y Presente -Ya! Es tiempo de pueblo-, la JTP y el IMT. Esa fue la semilla de la política con la que la JTP se desarrolló bajo el paraguas del Pacto Social. Uno de los principales artífices de la construcción de la agrupación que impulsó el conflicto fue Ricardo Sosa, quien militaba en Los Obreros y para el momento de la toma del astillero ya se había incorporado a Montoneros. La organización le dio centralidad al conflicto y Greco fue el encargado de seguirlo personalmente. El conflicto detonó cuando un accidente laboral se cobró la vida de uno de los trabajadores de la planta. Dos meses después, Cámpora anunciaba el lanzamiento del Pacto Social que ponía un freno a la lucha salarial. Astarsa aparecía entonces no sólo como un ejemplo de lucha que por su radicalidad había irrumpido en la escena pública-, sino que ofrecía la solución a la estrategia que la JTP podía desarrollar sin poner en cuestión el Pacto Social:

32 KUJNISKY, Eduardo. Entrevista. Entrevista cedida a CEDOPS, Lanús, Buenos Aires, 2009. 
congelaron los salarios por dos años. Nosotros estábamos a las re puteadas. O sea, nuestro principal conflicto con Perón fue ese. Porque el tipo congeló salarios, nosotros no participamos obviamente del Pacto ese, bueno, el Pacto fue entre empresarios y la dirección sindical. [...] Entonces ¿cómo impulsar la lucha de la JTP si no podías pelar por aumento salarial? Bueno, la solución me la dio la revista Ya! y Astarsa. Ellos no sabían que me daban nada, es decir, Astarsa no sabía que me daba la solución. Pero se junta Astarsa que peleaba por condiciones de trabajo, no peleaba por salarios (peleaba porque se murió un pibe laburando, ¿no?) entonces, ¿qué era lo que pedían? Mejora de las condiciones laborales, y lo objetaban. Viste, no pedían aumento salarial. ${ }^{33}$

Según este testimonio, la estrategia no fue bajada por la dirección de Montoneros. Surgió, por el contrario, de la propia JTP en esta articulación con Astarsa y Los Obreros. Naturalmente, se inscribió dentro de una pauta más general que sí surgió de la conducción montonera: la búsqueda de una forma de armonizar la construcción sindical con la vigencia del Pacto Social. Montoneros supo asimilarla y articularla con su estrategia más general, a la que ésta contribuía toda vez que permitía el crecimiento sindical. En este sentido y dando cuenta de la proyección nacional de la estrategia, Francisco Yofre, responsable de la regional Córdoba de la JTP, señala:

fue una estrategia nacional y nosotros [la regional Córdoba] la cumplimos a rajatabla. Y fue la que nos dio mucho crecimiento por ejemplo con los lecheros. Porque las condiciones eran muy insalubres. Poníamos mucho hincapié ahí. Eran muy sentidas... Había condiciones terribles. Todo lo que tiene que ver con el caucho. Ahí también era muy insalubre. En todas aquellas actividades las condiciones de higiene pesaban y ahí crecimos. No sobre lo salarial que estaba bajo el paraguas del Pacto Social. ${ }^{34}$

Aquello que comenzó desarrollándose de manera espontánea, casi fortuita y a tientas se institucionalizó luego con la designación de Saiegh en la Facultad de Medicina y con la construcción del IMT. Debe destacarse el rol jugado por el grupo porteño de Pasado y Presente, con lazos con Los Obreros, a través de la revista Ya! Es tiempo de pueblo. Ellos aportaron el conocimiento de la experiencia italiana respecto a la Medicina del Trabajo y el desarrollo de Comisiones Obreras de control de la salubridad, higiene y ritmos de producción. En los hechos, la revista ofició como una herramienta de propaganda de la JTP.

De este modo, la estrategia de lucha por salubridad e higiene le permitió a la JTP desarrollar una práctica antiburocrática allende la lucha salarial. Articulándose con el IMT, la JTP logró poner en pie una política sindical fundamentada en un conocimiento científico. Los profesionales del Instituto aportaban desde su especificidad, un conocimiento concreto que podía ser utilizado para la organización y la lucha de los trabajadores. La JTP era la mediación entre ambos, la encargada de "transformar todo eso en política" ${ }^{35}$, convirtiendo el conocimiento en consignas que movilizaran a los trabajadores. La disputa en ese plano permitió construir agrupaciones de base que enfrentaban a las conducciones vigentes con un reclamo sentido

33 GRECO, Guillermo. Entrevista. Entrevista cedida al autor. Capital Federal, 2016.

34 YOFRE, Francisco. Entrevista. Entrevista cedida al autor. Córdoba, 2016.

35 GRECO, op. cit. 
por los trabajadores de la rama. Además ofrecía una identificación con el peronismo, pues como hemos visto en los fundamentos del IMT, se exaltó y se utilizó la legislación laboral que se había creado en el periodo del peronismo clásico (1946-1955). Todo ello, sin chocar con las políticas del gobierno nacional. En resumidas cuentas, la estrategia de lucha por las condiciones de salubridad e higiene ofreció a la JTP una perspectiva antiburocrática, identificada con el peronismo y cimentada en el conocimiento científico.

\section{La puesta en práctica}

\section{Trabajadores navales}

ASTARSA no solo fue el disparador del IMT y de la estrategia de la JTP, sino también el lugar donde mayor desarrollo alcanzó esa experiencia. Como ya hemos descripto, el trabajo en los astilleros se desenvolvía con escasos mecanismos de seguridad e infrecuentes controles. La toma del astillero, de la mano de la agrupación de la JTP, había respondido a esos reclamos más que a lo salarial. Esa medida de fuerza había culminado en un éxito que se constituyó, a su vez, en un desafío para los trabajadores: la puesta en marcha de una Comisión Obrera de Control de Higiene y salubridad.

EI IMT inició su programa de estudio de accidentes de trabajo en la industria naval. A partir de la recopilación de antecedentes en estadísticas oficiales, entrevistas con las comisiones internas y la puesta en marcha de un equipo de trabajo interdiciplinario, nutrido de médicos e ingenieros navales, se procedió a estudiar tanto las afecciones producidas por los agentes ambientales contaminantes como por los ritmos de trabajo y la organización de la producción. Se buscaba hacer hincapié en la fatiga industrial como agente de los accidentes laborales, entendiendo que estos eran el resultado de una forma de organización del trabajo que obligaba a cumplir largas jornadas produciendo desgaste físico y psíquico.

Esta investigación y este enfoque de la fatiga en el trabajo fue un insumo fundamental para la lucha de la Agrupación "José María Alessio" de la JTP. Una de sus primeras batallas dentro la fábrica fue la declaración de la insalubridad y, en consecuencia, la reducción de la jornada laboral. Aquel trabajo sindical basado en la lucha por las condiciones de higiene y salubridad, que encontró en Astarsa su realización más acabada y se convirtió en un faro para el resto de la construcción de la JTP. La influencia de Astarsa se extendió a otros astilleros de la zona norte en muchos de los cuales la JTP fue ganando delegados: Mestrina, Reparaciones Navales y Fabrica de Construcciones Metalicas No Me, Acquamarina, Forte, Pagliettini.

\section{Mineros}

El programa de trabajadores mineros del IMT fue uno de los primeros en desarrollarse. La decisión de estudiar esta fracción de trabajadores partió de la constatación de un hecho que 
evidenciaría las duras condiciones de salubridad de ese tipo de trabajo: la inexistencia de jubilados dentro del gremio. ${ }^{36}$

Con un equipo de trabajo constituido por médicos, ingenieros ambientales y sociólogos, se realizaron visitas a dos minas de Jujuy: El Aguilar y Pirquitas. Se diseñó un esquema de proyecto abocado al estudio integral del ambiente de trabajo realizando mediciones sobre ruido, vibraciones, humedad y polvo, un estudio socioeconómico de la población minera y una indagación sobre la población trabajadora dada de baja. Estudios en lugares de trabajo constataron la existencia de condiciones de insalubridad con una alta prevalencia de neumoconiosis - enfermedad producida por incidencia del polvo en el aparato respiratorio - y se proyectó la tarea de impulsar modificaciones a la legislación laboral.

En paralelo al desarrollo de este programa de investigación, se produjo el nacimiento de la agrupación sindical de la JTP en la mina El Aguilar. ${ }^{37}$ Allí los magros salarios eran complementados con horas extras, lo que se traducía en jornadas de trabajo de 16 horas. Luego de la asunción de Cámpora, el gobierno intimó a la patronal a que cumpliera con la jornada laboral de 8 horas, lo cual -al no garantizar el nivel de salario percibido con las horas extras- redundó en un empeoramiento de las condiciones de vida de los trabajadores. Por este motivo, el 7 de noviembre se decidió en asamblea el inicio de un paro. La agrupación se concentró en difundir y organizar a los trabajadores para reclamar por las condiciones de salubridad e higiene, con denuncias de enfermedades vinculadas al polvillo acumulado en los pulmones, el rol de servicio a la patronal que cumple el médico de la empresa y la alta tasa de mortalidad en la zona.

El conocimiento y la experiencia ganada en el conflicto de El Aguilar sirvió también para la construcción de la JTP en otra mina importante, Hierro Patagónico de Río Negro. Allí los trabajadores protagonizaron una toma para exigir un aumento salarial que los liberara de cumplir horas extras, el mejoramiento de las viviendas ofrecidas por la empresa y la inmediata modificación de las condiciones de trabajo, que generaban accidentes fatales, intoxicación por gases y afecciones vinculadas al alto ruido ambiente. Tras varios días de conflicto se dictó conciliación obligatoria, consiguiéndose un plus salarial (inferior al solicitado), la resolución del problema de la vivienda y el reconocimiento de la insalubridad en todas las secciones.

\section{Ceramistas}

Otro de los programas de investigación del IMT que coincidió con un gremio en el cual la JTP alcanzó una amplia inserción fue el de ceramistas. Para el desarrollo de esta pesquisa se firmó un acuerdo con la Federación Ceramista que en diciembre de 1973 fue conquistada por la JTP.

36 TESTA, Mario. Entrevista. Entrevista cedida a CEDOPS, Lanús, Buenos Aires, 2010.

37 LA RECONSTRUCCIÓN la van a cuidar con dinamita. EI Descamisado, p. 12, 20 nov. 1973. SE SOLUCIONÓ el pleito de la mina "El Aguilar". Noticias, Buenos Aires, p. 8, 22 nov. 1973. 
Con una metodología que contempló la realización de entrevistas a delegados y trabajadores de Capital Federal y Gran Buenos Aires y el relevamiento de información clínica de obreros, el estudio del IMT verificó una serie de elementos que afectaban ostensiblemente la salud de los trabajadores. La causal más reiterada de enfermedades que se verificó fue la realización de "trabajo pesado", consistente en el paleo y carga de la pasta, el empuje de vagonetas, acarreo y ordenamiento de material. Ello se traducía en afecciones tales como fatiga física, hernia, problemas de columna, desgarros, fracturas y deformaciones en las manos. En igual sentido repercutía la posición del trabajo, quien siempre permanecía de pie. A ello se sumaba la presencia de varios factores ambientales contraproducentes. Por un lado, las altas temperaturas, la presencia de polvo en suspensión en el ambiente, el ruido constante y el contacto con plomo.

La lista Marrón, bajo el liderazgo de la Agrupación "Evita" de la JTP, impulsó estos reclamos levantando consignas por la eliminación del trabajo a destajo, en defensa de las condiciones de salubridad e higiene, la instalación de comedores y guarderías e igualdad de salario para las mujeres. ${ }^{38}$

\section{Telefónicos}

La investigación llevada adelante por el IMT entre los trabajadores telefónicos fue una de las más desarrolladas. El objetivo de dicha investigación fue indagar en las repercusiones del trabajo de las operadoras telefónicas en su salud, física pero sobre todo mental. El disparador de la pesquisa había sido la constatación de la existencia de una clínica de salud mental cuyos pacientes eran íntegramente operadoras telefónicas, lo que ponía en evidencia una insoslayable vinculación entre tipo de trabajo y la afección psíquica. Es interesante advertir que la composición exclusivamente femenina de la rama, no llevó a la incorporación de la dimensión del género a los trabajos del IMT ni a la práctica política de la JTP.

Para iniciar el programa se firmó un acuerdo con el gremio telefónico, estableciendo vinculación con su secretario general de la regional Capital, y, en particular, con la Comisión Femenina de aquella organización gremial; y con la gerencia de la empresa ENTEL. ${ }^{39}$ El equipo de trabajo se nutrió de sociólogos y especialistas en salud mental, quienes desarrollaron una metodología basada en tres actividades: visitas a las centrales telefónicas de Capital Federal y Gran Buenos Aires a fin de conocer los tipos de tareas que allí se realizan; recolección de datos estadísticos proporcionados por la División de Higiene y Medicina Laboral de la empresa ENTEL; y, realización de entrevistas a operadoras.

A partir de este estudio, sumado a las visitas y al análisis de los profesionales intervinientes, el IMT extrajo una serie de conclusiones. Por un lado, se evaluó que las condiciones materiales

38 REBELIÓN de los ceramistas. Ya! Es tiempo de pueblo, Buenos Aires, p. 31, 27 jun. 1973. OTRO SINDICATO recuperado. Política Obrera, Buenos Aires, p. 2, 2 nov. 1973.

39 INSTITUTO DE MEDICINA DEL TRABAJO. Anteproyecto de Convenio, 1973. 
de trabajo eran inadecuadas $y$, a pesar de no poder ser modificadas por las operarias, eran ellas las que cargaban con las consecuencias de esa deficiencia. Ello repercutía a nivel psicológico, pues se veían sometidas a fuertes impactos emocionales, sumados a la automatización de las respuestas que "bloquean la expresión verbal de los sentimientos suscitados, que son reprimidos o desplazados impidiendo su elaboración conciente" ${ }^{40}$. En lo físico, los asientos eran inadecuados, los dispositivos técnicos estaban deteriorados afectando la audición y el horizonte visual de las operarias no excedía el tablero, teniendo que fijar su mirada allí durante la totalidad de la jornada. A pesar de estar imposibilitado el dialogo y la interacción con las compañeras, el entorno estaba cargado de estímulos (luz, sonidos, movimientos), lo cual "se transforma en un instrumento que exige, excita y bloquea, inmovilizando y estimulando al mismo tiempo"41.

De todo ello se desprendieron una serie de propuestas generales de modificación, que se podían traducir rápidamente en un pliego de reivindicaciones para la agitación sindical. En lo ambiental, regulación de los sistemas de calefacción y refrigeración, sillas acordes a las necesidades de las operarias, implantación de sistemas de higiene y desinfección; en lo técnico, mejora de los equipos y líneas; en lo normativo, cubrir las vacantes necesarias para liquidar la sobrecarga, cambios en el sistema de relevo y del sistema de personal relevante, modificación del régimen disciplinario, flexibilidad en la fraseología; en materia de salud, implantar servicios médicos de urgencia, desarrollar una planificación preventiva y asistencia que permita la promoción, protección y rehabilitación de la salud física y mental.

En el gremio telefónico la JTP logró tener una presencia destacable. La militancia allí se inició en alianza con Julio Guillán quien, con su Lista Marrón, era caracterizado inicialmente como parte del "peronismo combativo" pues había participado de la experiencia de la CGT-A. La ruptura se produjo en agosto de 1973 y fue encabezada por Celestino Blanco y Luis Arscuchin, delegado general y subdelegado general del edificio "República", sede central de Entel en la que se desempeñan 4500 trabajadores. ${ }^{42}$ Así nació la agrupación "Felipe Vallese" de Telefónicos y la Lista Azul-Naranja.

Si bien nuestras fuentes no arrojan información detallada sobre conflictos o actividades de las trabajadoras operadoras, Greco confirma que los resultados de la investigación del IMT se plasmaron en la construcción sindical de la JTP. Sí encontramos en los órganos de difusión montoneros que la agrupación de Telefónicos impulsó los reclamos de seguridad de los trabajadores de las cuadrillas de instalación y reparación de cableado. Del mismo modo se denunciaron, las condiciones de trabajo en las sucursales de Entel, donde se registraban altas niveles de temperatura, ruido, escasa iluminación, falta de higiene en baños e insalubridad en el sector de carga de baterías. Por ello en diciembre de 1973 los

$\overline{40}$ INSTITUTO DE MEDICINA DEL TRABAJO. Un año de realizaciones, 1974, p. 8.

41 Ibidem, p. 9.

42 EDIFICIO Evita. EI Descamisado, Buenos Aires, p. 12, 7 ago. 1973. QUE SE ROMPAN los contratos, con los yanquis no hay más tratos. El Descamisado, Buenos Aires, p. 21, 28 ago. 1973. 
trabajadores de la sucursal Paternal-Gaona fueron al paro, exigiendo el reacondicionamiento integral del edificio. ${ }^{43}$

\section{Textiles}

La constatación de la importancia económica de la industria textil, y la tradicional identificación de esta rama de la producción con las afecciones a la salud, motivó a que el IMT desarrollara un programa de investigación en el rubro. Para llevarla a cabo se inició el plan de trabajo con entrevistas a miembros de la comisión interna de ciertos establecimientos, a los fines de obtener información sobre el proceso productivo, el ambiente de trabajo y la sintomatología más frecuente. Luego, analizando el proceso de trabajo, se identificó dos etapas que se diferencian por sus labores y por el efecto específico que pueden llegar a generar en la salud de los obreros. La primera de ellas comprendía las tareas que iban desde la manipulación del algodón en bruto hasta llegar a la tela cruda. La segunda, continúa con aquel y culmina en el producto textil terminado. Como puede apreciarse, más allá de que el programa refiera a "industria textil" lo que se observa es que el objeto de análisis son tanto los procesos de producción de tela (cuyos trabajadores se organizan tradicionalmente en la Asociación Obrera Textil - AOT) y los de confección de prensa (que se nuclea dentro del Sindicato de Obreros de la Industria del Vestido - SOIVA). El primero de los procesos, afectaría la salud de los trabajadores a partir de elementos ambientales como el ruido - que en la sección tejeduría impediría la audición a más de un metro de distancia -, la pelusa que se desprende de la manipulación del algodón en varias secciones y la humedad ambiente, que es una condición necesaria para la preservación de la materia prima. Además de ello, se trabajaba con un elevado ritmo de producción, dado que se establecían metas diarias muy altas, se producían frecuentemente interrupciones por corte de hilos o fallas de la maquinaria y cada trabajador debía operar unos 20 telares en simultáneo.

En cuanto al segundo grupo de tareas, en la sección droguería y tintorería existía un mayor riesgo de intoxicación por la exposición a sustancias químicas en forma de polvo, líquidos o vapores, fundamentalmente por el uso de ácidos y solventes. Allí también afectaba la pelusa que desprendida de la tela y el desarrollo de tareas de trabajo pesado con el movimiento de rollos de material de entre 90 y 120 kilos.

El reconocimiento de estos riesgos llevó al IMT a postular como posibles y frecuentes una serie de afecciones en los trabajadores: deterioro auditivo por la exposición al ruido, neumoconiosis por aspiración de polvo, intoxicación química, patologías ortopédicas asociadas a las posiciones corporales en el proceso de trabajo y la realización de trabajo pesado y, problemas psicopatológicos por los horarios rotativos (se desarrollan tres turnos que quincenalmente se rotan), la exposición al ruido y los altos ritmos de producción.

43 LAS BASES se organizan. Nuevo Hombre, Buenos Aires, p. 3, 13 dic. 1973. 
Hugo Goldsman, sociólogo, militante montonero y miembro de la JTP fue el responsable político de las agrupaciones vinculadas al gremio textil y del vestido. En tanto tal, fue el encargado de coordinar este programa de investigación del IMT con el trabajo de base en las empresas textiles. ${ }^{44}$ En esos gremios, las agrupaciones de base ligadas a Montoneros impulsaron los reclamos por salubridad e higiene. Desde las agrupaciones del vestido se buscó hacer pie en Comercio Internacional, una empresa textil que empleaba unAs 270 trabajadoras mujeres, impulsando una serie de demandas vinculadas a la salubridad, higiene y seguridad de la planta. En particular, se cuestionaba la "actitud propatronal" de los médicos de planta que "trabajan de acuerdo con el Jefe de Personal y nos quieren curar de cualquier cosa una 'pastillita', que es siempre la misma", ${ }^{45}$ la insalubridad en secciones como cuero y tinturas y en particular las altas temperaturas que se soportan en la sección planchado. A su vez, en estas ramas, la JTP también desarrolló trabajo en Textil Bossi Toallas, Algodonera Argentina, Sasson y Grafa.

\section{Metalmecánicos}

El programa de investigación sobre la salud de los trabajadores metalmecánicos, surgió del pedido de trabajadores de esas ramas que se acercaron al IMT, y por la necesidad de tener un balance sobre las condiciones de trabajo en las ramas principales de la actividad económica del país. Inicialmente la investigación comenzó limitada a un factor: la intoxicación crónica por plomo, un metal pesado con una gran difusión en la industria. Posteriormente, se buscó profundizar la investigación atendiendo a los ritmos de producción, la línea de montaje, los incentivos materiales a la producción, los horarios rotativos, entre otros, con el objetivo de trascender la concepción de la intoxicación como "enfermedad profesional". Si bien este programa no alcanzó a desarrollarse completamente, debido al abrupto cierre del IMT, en su planificación se contemplaba el estudio del calor crónico, la fatiga industrial y las alteraciones biológicas producto de los horarios rotativos.

A los fines de cumplir con estos objetivos se creó un equipo de médicos clínicos, toxicólogos, psicólogos, ingenieros, sociólogos, economistas, bioquímicos y asistentes sociales. La etapa inicial se desarrolló con un relevamiento del estado de salud de trabajadores de dos empresas metalúrgicas y dos automotrices. No han perdurado, sin embargo, registros que permitan reconstruir las conclusiones del programa.

Por los testimonios orales de los diversos protagonistas de la experiencia del IMT, sabemos que este programa se basó en el estudio de la Fundición Insud, la fábrica de acoplados Pratti-Vázquez-Iglesias, y de la automotriz Fiat (planta Caseros), para esta última se firmó un convenio con la conducción del Sindicato de Trabajadores de Fiat Caseros (IMT y SITRAFIC, 1973).

44 GRECO, op. cit.

45 PIRATAS internacionales. El Descamisado, Buenos Aires, p. 13, 27 nov. 1973. 
El caso de Insud fue uno de los más conocidos. Por su actividad fundamental, la fundición de plomo, la planta de la empresa instalada en La Matanza poseía uno de los índices más altos de saturnismo entre sus trabajadores, llegando a contarse 79 trabajadores enfermos de un plantel total cercano a los 250 empleados. Dado que los hornos y chimeneas emanaban gases tóxicos a las barriadas circundantes, la lucha por la salubridad se extendió allende las puertas de la fábrica. Hacia fines de 1973, los trabajadores habían hecho la correspondiente denuncia ante la Dirección de Salud Pública, de la que no obtuvieron respuesta. En el mes de diciembre realizaron una primera manifestación en puerta de fábrica, reclamando por la urgente mejora de las condiciones de salubridad en la planta, y al mes siguiente fueron al Congreso para insistir en su denuncia. En el marco de este proceso de lucha, los trabajadores de Insud entraron en contacto con el IMT, que inicialmente les brindó una ayuda asistencial para dar una inmediata aunque parcial solución a sus afecciones.

La JTP estuvo presente en el conflicto, intentando hacer pie en la fábrica. Con todo, y a pesar de acompañar desde el comienzo a los trabajadores de la planta, el peso mayoritario en la comisión interna fue patrimonio del PRT-ERP. Esto puede deberse a que uno de los principales promotores de la línea de investigación en Insud dentro del IMT, fue Donalisio, quien tenía relación con el Movimiento Sindical de Base. ${ }^{46}$

Del relevamiento de nuestras fuentes, no encontramos conflictos en Pratti-VázquezIglesias y Fiat Caseros durante el período, pero sí tenemos constancia que allí hubo delegados de JTP: Roberto Olivestre en la primera, Roberto Giménez en la segunda. Por otro lado, la segunda automotriz donde se realizó la investigación del IMT fue la planta instalada en San Justo de la firma Chrysler. Allí se había proletarizado alcanzando a ser elegido delegado y miembro de la comisión interna "pancho" Zanandrea, quien provenía de Los Obreros. En esa empresa, la JTP impulsaba la agrupación "Eva Perón” que surgió hacia 1972, y en 1973 había logrado introducir representantes en el cuerpo de delegados y en la comisión interna. Desde allí denunció el incumplimiento del convenio colectivo de trabajo, la falta de higiene y las condiciones de salubridad e higiene. Esa prédica cobró fuerza en enero de 1974, cuando en la sección horma y chapa un obrero recibió el impacto de una piedra esmeril, que le destrozó el cráneo y un ojo. Por la ausencia de equipamiento, los compañeros de trabajo debieron trasladarlo en una lona y uno de ellos debió conducir la ambulancia hasta el hospital.

La JTP hizo allí una denuncia detallada. En la sección pintura, un $40 \%$ de los trabajadores sufrían dolores de cabeza y afecciones digestivas por intoxicación por plomo gracias a la pintura suspendida en el ambiente, que no es correctamente filtrada por los extractores. También padecen sinusitis y afecciones en las cuerdas vocales unos diez trabajadores por el uso de diluyentes. Se registraban además altas temperaturas en el conjunto de la planta, alcanzado los $40^{\circ}$, por la ausencia de ventilación y refrigeración. A todo ello se sumaba un gran ruido ambiente constante producto del movimiento de los pistones y martillos neumáticos que

46 DONALISIO, Roberto. Entrevista. Entrevista cedida a CEDOPS, Lanús, Buenos Aires, 2011. 
generan zumbidos constantes y conllevan una gradual perdida de la audición. En la sección de lijado se trabajaba con cortinas de agua fría que generaban dolores reumáticos. También las malas condiciones de las herramientas, sin renovación hace más de 30 años, carecían de mecanismos de seguridad y producían accidentes como el que detonó el conflicto, además de un mayor esfuerzo por parte del operario que generaba un mayor agotamiento y posiciones incorrectas que deforman la columna. Todo ello agravado por jornadas de no menos de 8 horas y con un ritmo de producción en aumento. Amén de la ausencia de un servicio médico orientado "a comprobar si los obreros 'mientes"” y "suministrarles una pildorita que sirve tanto para 'curar' una enfermedad cardíaca como un resfrío". ${ }^{47}$

\section{Conclusiones}

LA DEFENSA DEL GOBIERNo de Cámpora y Perón, que había puesto en vigencia el Pacto Social dejando congelados los ingresos obreros, obligó a la JTP a buscar una estrategia de construcción sindical que trascendiera lo salarial. Requería entonces algún tipo de demanda que movilizara a los trabajadores y que permitiera, a través de ello, el desalojo de las conducciones burocráticas. La respuesta a este interrogante se encontró en la experiencia de Astarsa, donde se desarrolló un importante conflicto a raíz de un incidente que le costó la vida a un operario, y en el aporte de los médicos de El Obrero.

La política que se dio la JTP para crecer, sin cuestionar a Perón y su Pacto Social, fue realmente efectiva y muestra que Montoneros no fue simplemente un aparato militar ajeno a la clase obrera. Logró atraer a capas de la intelectualidad, que fueron convocados para construir desde su campo específico de acción. Ese conocimiento fue un insumo que le permitió a la organización estar en mejores condiciones para impulsar los reclamos por la salubridad y la higiene en un momento en que estos cobraban centralidad. Así ganó seccionales de sindicatos, comisiones internas y cuerpos de delegados. Con ello, podía rivalizar con la burocracia sindical peronista, hacer crecer su activismo y estar en mejores condiciones para la disputa dentro del Movimiento, sin enfrentar al gobierno. Servía entonces a la estrategia que se había propuesto.

De este modo, creemos haber contribuido a profundizar el terreno de los estudios sobre las prácticas sindicales en los años '70 y la relación entre las izquierdas y el movimiento obrero argentino, en un escenario verdaderamente conflictivo. Como se ha podido ver, las izquierdas, en este caso Montoneros y su JTP, vieron alteradas sus posibilidades de desarrollo en el contexto del congelamiento salarial vigente. Sin embargo, ese obstáculo no impidió la realización de su empresa política, sino que obligó al despliegue de nuevas propuestas tácticas. Estudios futuros podrán evaluar en qué medida esta forma de acción fue original

47 LA BUROCRACIA juega en el mismo equipo que los patrones. El Descamisado, Buenos Aires, p. 14, 2 abr. 1974. 


\section{Guido Lissandrello}

de la organización que hemos estudiado o, por el contrario, fue un fenómeno extendido al conjunto del universo de las izquierdas. De todos modos, la particular articulación con el Instituto de Medicina del Trabajo posiblemente haya posicionado a Montoneros en un espacio privilegiado para crecer en el terreno de las demandas por salubridad e higiene.

Recebido em: 08/07/2020

Aprovado em: 25/07/2020 